\title{
Papers
}

\section{Breast cancer mortality in Copenhagen after introduction of mammography screening: cohort study}

Anne Helene Olsen, Sisse H Njor, Ilse Vejborg, Walter Schwartz, Peter Dalgaard, Maj-Britt Jensen, Ulla Brix Tange, Mogens Blichert-Toft, Fritz Rank, Henning Mouridsen, Elsebeth Lynge

\begin{abstract}
Objectives To evaluate the effect on breast cancer mortality during the first 10 years of the mammography service screening programme that was introduced in Copenhagen in 1991.

Design Cohort study.

Setting The mammography service screening programme in Copenhagen, Denmark.

Participants All women ever invited to mammography screening in the first 10 years of the programme. Historical, national, and historical national control groups were used.

Main outcome measures The main outcome measure was breast cancer mortality. We compared breast cancer mortality in the study group with rates in the control groups, adjusting for age, time period, and region.

Results Breast cancer mortality in the screening period was reduced by $25 \%$ (relative risk $0.75,95 \%$ confidence interval 0.63 to 0.89 ) compared with what we would expect in the absence of screening. For women actually participating in screening, breast cancer mortality was reduced by $37 \%$.

Conclusions In the Copenhagen programme, breast cancer mortality was reduced without severe negative side effects for the participants.
\end{abstract}

\section{Introduction}

In the overview of five randomised trials from Sweden, a reduction of $29 \%$ was found in breast cancer mortality in women aged 50-69 at randomisation after a follow up of 5-13 years. ${ }^{1}$ Organised, population based, mammography service screening was introduced on the basis of these results in Copenhagen, the capital of Denmark, in $1991 .^{2}$ Since then the validity of the trial results and the justification of mammography screening have been debated intensively. ${ }^{3}$ Furthermore, the adaptation of trial results to routine health care is not straightforward. Examining whether the screening programmes actually reduce mortality due to breast cancer is therefore important.

In Denmark, mammography screening was introduced in only three out of 16 administrative regions. The regions without a mammography screening programme thereby provide a natural control group during the full period of follow up. In addition, opportunistic screening has been limited. ${ }^{5}$ Taking advantage of this "natural experiment," and using the nationwide population and health registers in Denmark, we developed a method to determine the effect of mammography service screening on breast cancer mortality. ${ }^{6}$ We present here the results of the first 10 years of screening in Copenhagen.
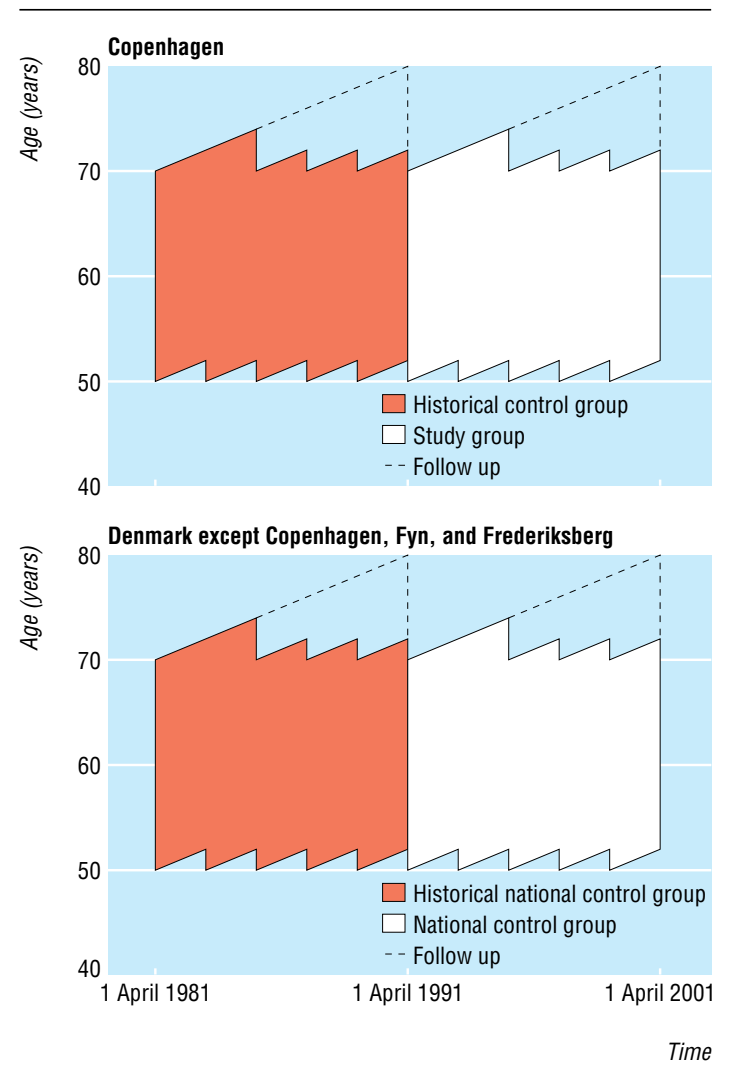

Fig 1 Study design for the evaluation of mammography screening in Copenhagen, Denmark

\section{Methods}

Model

We used a Poisson regression model with a study group, a historical control group, a national control group, and a historical national control group (fig 1 ). ${ }^{6}$ We studied the effect of invitation to as well as participation in screening. The end point was mortality due to breast cancer.

The study group included women invited to screening in Copenhagen during the first five invitation rounds from 1 April 1991 to 31 March 2001. The screening interval was two years. The target group included about 40000 women aged 50-69 at the start of each invitation round. The second invitation round included women aged 50-71, but in subsequent rounds no more women above the age of 69 were invited. The first invitations 
Table 1 Study areas and time periods of the study and control groups

\begin{tabular}{lll} 
Time period & Copenhagen & $\begin{array}{l}\text { Denmark outside screening } \\
\text { regions* }\end{array}$ \\
\hline Pre-screening period 1981-91 & Historical control group & $\begin{array}{l}\text { Historical national control } \\
\text { group }\end{array}$ \\
\hline Screening period 1991-2001 & Study group & National control group
\end{tabular}

*Three out of 16 administrative regions in Denmark—Copenhagen, Fyn, and

*Three out of 16 administrative regions in Denmark-Copenhagen, Fyn, and
Frederiksberg - had mammography screening in the 1990s. All three regions were excluded

from the national and the historical national control groups.

went to women born on 1 January, the following ones to women born on 2 January, and so on, irrespective of their year of birth. Women moving to Copenhagen received their invitation shortly after their arrival, unless their date of birth was scheduled for invitation later in the round. Invitations did not go to women if they moved out of Copenhagen before their date of birth was scheduled for invitation. Once a woman had been invited to screening, she remained in the study group even if she moved to another region. We followed up all women from their first date of invitation until death, emigration, or 31 March 2001. We excluded women with prevalent breast cancer before their first invitation date. In total, 30362 women, equivalent to $71 \%$ of women in the target population, participated in the first invitation round, a percentage that fell slightly over rounds as women could ask not to be reinvited to the programme. ${ }^{7}$

For all three control groups we constructed five, two year, "pseudo-invitation" rounds and allocated pseudo-invitation dates by using the invitation system from the study group. We followed up women from their first pseudo-invitation date until death, emigration, or end of follow up, which was 31 March 1991 for the historical and the historical national control groups, and 31 March 2001 for the national control group. We excluded women with prevalent breast cancer before their first pseudo invitation date.

Table 1 shows the regions and periods covered by each of the study and control groups.

\section{Data}

We retrieved data on women invited to the programme from the Copenhagen mammography screening register and checked them with the central population register. We "constructed" the control groups from the individual records with both present and past addresses in the central population register. We identified women with prevalent breast cancer on their invitation date or pseudo-invitation date from the Danish cancer register. We followed up the groups for deaths and emigrations in the central population register. Data on underlying cause of death came from the cause of death register, where data were available only to 31 March 2001, which was therefore the end of follow up. We used the personal identification number issued to all residents of Denmark to link registers.

\section{Statistical analysis}

To analyse the effect of invitation to screening, we compared breast cancer death rates in the study group and the control groups, adjusting for age (age during follow up), time period, and region. We used a Poisson regression model with the variables five year age group, exposure, period, and region. ${ }^{6}$ Although we were thereby able to control for time trends and regional differences, we were not able to separate out a potential effect of an interaction between the two from the effect of screening. In interpreting the results we therefore had to take into consideration additional data on a potential interaction effect.

We performed a corresponding analysis for participants in screening. To correct the relative risk (RR) for participants for selection bias we divided it by a correction factor, $R R_{\text {corrected }}$, calculated from the following equation:

$$
1=R R_{\text {corrected }} * w_{\text {participans }}+R R_{\text {non-attenders }} * w_{\text {no }}
$$

where $w_{\text {participants }}$ is the proportion of the total number of person years in the screening period contributed by the participants, and $w_{\text {non-attenders }}$ is the corresponding proportion for the nonattenders. $R R_{\text {non-attenders }}$ is the relative risk for the non-attenders calculated in the same way as for the total invited population, but including only the non-attenders in the study group. The corrected relative risk for participants reflects the effect of participation in screening for the population of participants.

\section{Results}

For the period before screening started, Copenhagen had a significantly higher mortality due to breast cancer than the rest of Denmark (relative risk 1.22, 95\% confidence interval 1.10 to 1.35), although there was some variation by age group. This had changed in the screening period, where Copenhagen had a lower breast cancer mortality than the rest of Denmark (0.91, 0.80 to 1.05). When we compared Copenhagen in the screening period with the period before screening, the relative risk was significantly lower than $1(0.80,0.68$ to 0.94$)$. When we compared the rest of Denmark in the screening period with the period before screening, the relative risk was 1.05 (0.99 to 1.11), again with some variation by age group. When we estimated the effect of the combination of invitation to screening and the interaction term between period and region adjusted for age, period, and region, the relative risk was 0.75 ( 0.63 to 0.89 ; table 2 ).

We estimated the cumulative effect of the combination of invitation to screening and the interaction term between period and region by year of follow up and adjusted for age at entry, period, and region (fig 2). Significance was reached after six years of follow up.

For the participants the estimated effect of combining participation in screening and the interaction term between period and region adjusted for age, period, and region resulted in a relative risk of $0.60(0.49$ to 0.74$)$. On the other hand, women invited to screening who did not participate had a relative risk of 1.15 (0.91 to 1.46$)$. On this basis, we estimated that in a situation without screening, participants would be a selected part of the population, with a relative risk of 0.95 compared with the total population. When we adjusted for this selection bias, the relative risk for the participants was 0.63 .

When we used the same method as in the breast cancer mortality analysis, the invited population had a total cancer mortality (excluding breast cancer) close to that expected without screening (relative risk $0.96,0.91$ to 1.01 ).

\section{Discussion}

Breast cancer mortality in Copenhagen was reduced significantly after mammography screening had been introduced. We used individual data to estimate the screening effect, controlling for time trends and regional differences in breast cancer mortality.

The method of this study is presented in detail in another paper, where it was validated by applying it to total mortality as an end point. ${ }^{6}$ In this paper we consider aspects of the method specific for breast cancer mortality as an end point.

A $25 \%$ reduction is the best possible estimate of the size of the mortality reduction achieved with mammography screening. It is, however, necessary to consider the role of the interaction term between period and region also inherent in the $25 \%$ 


\begin{tabular}{|c|c|c|c|c|c|c|c|}
\hline Study group & $50-54$ & $55-59$ & $60-64$ & $65-69$ & $70-74$ & $75-79$ & All age groups \\
\hline $\begin{array}{l}\text { No of breast cancer } \\
\text { deaths }\end{array}$ & 9 & 34 & 43 & 53 & 56 & 28 & 223 \\
\hline Person years & 64144 & 92734 & 83510 & 87408 & 77427 & 25600 & 430823 \\
\hline $\begin{array}{l}\text { Breast cancer mortality } \\
\text { per } 100000 \text { person } \\
\text { years }\end{array}$ & 14 & 37 & 51 & 61 & 72 & 109 & 52 \\
\hline \multicolumn{8}{|l|}{ National control group* } \\
\hline $\begin{array}{l}\text { No of breast cancer } \\
\text { deaths }\end{array}$ & 89 & 434 & 516 & 535 & 545 & 214 & 2333 \\
\hline Person years & 767111 & 1067778 & 906943 & 826254 & 635385 & 192946 & 4396417 \\
\hline $\begin{array}{l}\text { Breast cancer mortality } \\
\text { per } 100000 \text { person } \\
\text { years }\end{array}$ & 12 & 41 & 57 & 65 & 86 & 111 & 53 \\
\hline \multicolumn{8}{|l|}{ Historical control group } \\
\hline $\begin{array}{l}\text { No of breast cancer } \\
\text { deaths }\end{array}$ & 22 & 45 & 82 & 104 & 128 & 57 & 438 \\
\hline Person years & 57669 & 113143 & 139065 & 155697 & 128454 & 40196 & 634224 \\
\hline $\begin{array}{l}\text { Breast cancer mortality } \\
\text { per } 100000 \text { person } \\
\text { years }\end{array}$ & 38 & 40 & 59 & 67 & 100 & 142 & 69 \\
\hline \multicolumn{8}{|c|}{ Historical national control group $\dagger$} \\
\hline $\begin{array}{l}\text { No of breast cancer } \\
\text { deaths }\end{array}$ & 104 & 443 & 485 & 491 & 418 & 182 & 2123 \\
\hline Person years & 577528 & 931245 & 916923 & 838476 & 608008 & 182824 & 4055004 \\
\hline $\begin{array}{l}\text { Breast cancer mortality } \\
\text { per } 100000 \text { person } \\
\text { years }\end{array}$ & 18 & 48 & 53 & 59 & 69 & 100 & 52 \\
\hline \multicolumn{8}{|c|}{ Relative risk estimates ( $95 \%$ confidence interval) } \\
\hline $\begin{array}{l}\text { Study group compared } \\
\text { with national control } \\
\text { group* }\end{array}$ & 1.21 (0.61 to 2.40$)$ & 0.90 (0.64 to 1.28$)$ & 0.91 (0.66 to 1.24$)$ & $0.94(0.71$ to 1.24$)$ & 0.84 (0.64 to 1.11$)$ & 0.99 (0.67 to 1.46$)$ & 0.91 (0.80 to 1.05$)$ \\
\hline $\begin{array}{l}\text { Historical control group } \\
\text { compared with } \\
\text { historical national } \\
\text { control group } \dagger \\
\end{array}$ & $2.12(1.34-3.36)$ & 0.84 (0.62 to 1.14$)$ & $1.11(0.88$ to 1.41$)$ & $1.14(0.92$ to 1.41$)$ & $1.45(1.19$ to 1.77$)$ & $1.42(1.06$ to 1.92$)$ & $1.22(1.10$ to 1.35$)$ \\
\hline $\begin{array}{l}\text { Study group compared } \\
\text { with historical control } \\
\text { group }\end{array}$ & $0.37(0.17-0.80)$ & 0.92 (0.59 to 1.44$)$ & 0.87 (0.60 to 1.26$)$ & $0.91(0.65$ to 1.26$)$ & $0.73(0.53$ to 0.99$)$ & 0.77 (0.49 to 1.21$)$ & 0.80 (0.68 to 0.94$)$ \\
\hline $\begin{array}{l}\text { National control group* } \\
\text { compared with } \\
\text { historical national } \\
\text { control group } \dagger \\
\end{array}$ & $0.64(0.49-0.86)$ & 0.85 (0.75 to 0.98$)$ & 1.08 (0.95 to 1.22$)$ & $1.11(0.98$ to 1.25$)$ & $1.25(1.10$ to 1.42$)$ & $1.11(0.91$ to 1.36$)$ & 1.05 (0.99 to 1.11$)$ \\
\hline $\begin{array}{l}\text { Combined effect of } \\
\text { invitation to } \\
\text { screening and } \\
\text { interaction between } \\
\text { region and period }\end{array}$ & $0.57(0.25-1.30)$ & 1.08 (0.68 to 1.72$)$ & $0.81(0.55$ to 1.20$)$ & $0.82(0.58$ to 1.17$)$ & 0.58 (0.41 to 0.82$)$ & $0.69(0.42$ to 1.13$)$ & 0.75 (0.63 to 0.89$)$ \\
\hline
\end{tabular}

†Historical national control group (Denmark except Copenhagen, Fyn, and Frederiksberg).

estimate, which could in theory reflect unsynchronised improve-

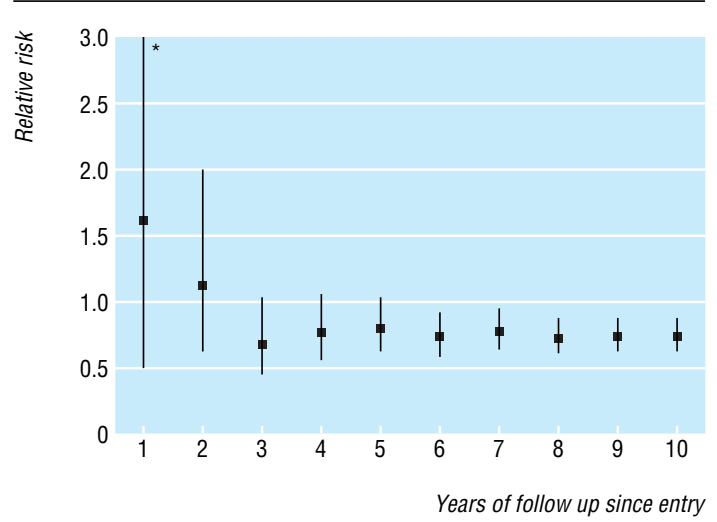

* The $95 \%$ confidence interval after 1 year of follow up was 0.51 to 5.05

Fig 2 Estimated effect on breast cancer mortality of invitation to mammography screening in Copenhagen, cumulated over years of follow up ments in treatment. But since 1977 diagnostic and therapeutic strategies have been organised nationwide in the setting of the Danish breast cancer cooperative group. ${ }^{8}$ This means that all hospital departments involved in diagnosis and treatment of breast cancer patients have used uniform guidelines for histopathology, surgery, radiotherapy, and systemic therapy. Breast cancer patients from the screening region have therefore been offered the same treatment as breast cancer patients from the national control group, both during the screening period 19912001, and during the historical control period 1981-91. This was confirmed by a study that found that survival from breast cancer did not differ between Copenhagen and the rest of Denmark after the start of the Danish breast cancer cooperative group in 1977. ${ }^{9}$ In addition, a study examining time trends in breast cancer mortality in the pre-screening period found no interaction or only a negligible interaction between period and region. ${ }^{10} \mathrm{On}$ this basis it is reasonable to expect the interaction term between period and region to be small. We also calculated the interaction term for the non-screening counties in Denmark. Copenhagen 
had the largest drop in mortality and was the only region where this reduction reached significance.

\section{Comparison with other countries}

England and Wales-In England and Wales, Blanks et al evaluated the effect of the NHS breast screening programme on breast cancer mortality by comparing observed mortality in the screening period with that predicted for a situation without screening. ${ }^{11}$ Women aged 50-64 are invited to screening every three years. The programme was built up gradually, with a prevalence round from 1988 to 1995 . In 1998, the observed mortality in the age group 55-69 was 21\% lower than the mortality predicted without screening, but the authors estimated that two thirds of the reduction could be attributed to the introduction of adjuvant systemic therapy and earlier presentation outside the screening programme. They were unable to exclude breast cancers diagnosed before the screening programme started, and this diluted their estimated effect of screening. With the short follow up and the dilution of the estimate by breast cancers diagnosed before start of screening, it seems reasonable that, so far, the effect attributed to screening was low.

Netherlands - In the Netherlands, the first screening programmes started in the late 1980s. By 1997 all women aged 50-69 in the Netherlands were covered by a screening programme. Otto et al compared mortality trends in the screening period with those in the pre-screening period. ${ }^{12}$ For women aged 55-74, the rates had dropped by $20 \%$ in 2001 compared with 1986 to 1988 . As they pointed out, this estimate was diluted by the fact that they were not able to exclude breast cancers diagnosed before initiation of screening, but they argued that adjuvant systemic therapy was unlikely to be the cause of the decline, since in regions where screening started after 1995 the death rates continued to rise up to one year after implementation. Other changes that may have affected breast cancer mortality in the recent period could, however, not be taken into account. The effect may seem surprisingly large, considering that it was not possible to use refined mortality, but by 2001 many of the breast cancer deaths would probably come from breast cancers diagnosed after start of screening.

Sweden-In Sweden, Jonsson et al compared counties that started screening in 1986-7 with counties that started in 1993 or later. ${ }^{13}$ They too were unable to avoid inclusion of breast cancers diagnosed between start of the screening programmes and the individual invitations, but they estimated the magnitude of the problem and adjusted their estimates accordingly. To adjust for geographical differences between the study and control groups, they used a reference period. This was based on an assumption of multiplicative effects between regions and periods (no interaction). The authors estimated a 20\% reduction in breast cancer mortality in women aged 50-69 at screening. Their mean follow up since start of screening was 10.6 years. Duffy et al estimated the effect on breast cancer mortality of invitation to screening in seven Swedish counties. ${ }^{14}$ Six counties invited women aged 40-69, and one county invited women aged 50-69. They selected a starting date for each county, with as little screening as possible taking place before it and high coverage as soon as possible after that date. Breast cancers diagnosed before that date were excluded. The screening period was compared with a pre-screening period of the same length, taking changes in death rates over time in the pre-screening period into account, and comparing the pre-screening period with the non-attenders, correcting for a self selection bias by using an estimate from the randomised trials. For counties with over 10 years of screening, the authors estimated a $32 \%$ reduction in breast cancer mortality among women invited in the screening period compared with the pre-screening period. For counties with 10 years of screening or less, the estimated reduction was $18 \%$. Although none of these studies is completely unbiased, all of them are consistent with the $25 \%$ reduction estimated in our study.

\section{Specific considerations}

Breast cancer mortality was significantly higher in Copenhagen than in the rest of Denmark in the pre-screening period. This is probably due to regional differences in risk factors since diagnostic procedures and treatment have been organised nationwide since $1977 .{ }^{8}$

The age group 55-59 differed from the remaining age groups with a relative risk of 1.08 (0.68 to 1.72$)$. Although the confidence interval is broad, it is noteworthy that this is in line with the lack of an effect for women aged 50-54 at randomisation found in the second Swedish overview and in the Edinburgh trial. ${ }^{15}$ Nyström et al propose that hormonal factors could play a part. ${ }^{15}$ Further research is warranted.

The argument has been put forward that a reduction in breast cancer mortality in the study groups of mammography screening trials was partly due to misclassification of breast cancer deaths as deaths from other cancers for the study groups. ${ }^{4}$ This was not the case in our study, as the relative risk was close to 1 for mortality due to other cancers.

\section{Mortality reduction in participants}

The non-participants in our study had a slightly, although not significantly, higher breast cancer mortality than the general population. The resulting selection bias does not affect the results for all invited women but merely the results for the participants. Adjusting for this selection bias resulted in a relative risk for the participants of 0.63 - that is, a mortality that is $37 \%$ lower than that expected without screening was seen among participants in the Copenhagen screening programme.

\section{Possible negative effects of mammography screening}

Mammography screening is justifiable only if it reduces mortality due to breast cancer. However, this may be a necessary requirement, but it is not a sufficient one, since mammography screening also has some potential negative side effects. It is therefore important to add that the introduction of mammography screening in Copenhagen did not lead to an increase in breast cancer incidence apart from the expected prevalence peak. ${ }^{5}$ In the first four invitation rounds, ductal carcinoma in situ constituted only $11 \%$ of the detected cases, owing to a deliberately conservative attitude towards supposedly benign microcalcifications. ${ }^{7}$ The intensity of the programme has been high, with a two year screening interval and a relatively high detection rate. ${ }^{7}$ The false positive rate has been relatively high$5.6 \%$ after the first screen, $2.9 \%$ after the second screen, and $1-2 \%$ after subsequent screens. ${ }^{7}$ By far most of these findings are, however, sorted out at the assessment, and by now, about $80 \%$ of women having surgery had invasive breast cancer or ductal carcinoma in situ. ${ }^{7}$ The proportionate interval cancer rate after the first invitation round in Copenhagen was low compared with that of other European programmes. ${ }^{17}$ The intensity of the programme and short term performance indicators have been described in detail in earlier publications. ${ }^{25717}$

\section{Conclusion}

In the Copenhagen mammography screening programme it has been possible to reduce breast cancer mortality by an estimated $25 \%$, and at the same time to avoid severe negative side effects for the participants. 


\section{What is already known on this subject}

Most studies of randomised controlled trials have indicated that mammography screening leads to a reduction in breast cancer mortality for certain age groups

Evidence is now starting to emerge on the effect of mammography screening in routine healthcare settings, such as service screening

\section{What this study adds}

This study of mammography service screening controlled for regional and historical differences

Patients with breast cancers diagnosed before they had received the first invitation to screening were excluded

The 25\% reduction of breast cancer mortality found in this study therefore indicates that mammography service screening can reduce breast cancer mortality

Contributors: All the authors have contributed to the planning and reporting of the work described in the article. AHO is the guarantor.

Funding: Danish Medical Research Council; Centre for Evaluation and Medical Technology Assessment in the Danish National Board of Health; the European Commission, Directorate-General SANCO, and Copenhagen Hospital Corporation.

Competing interests: None declared.

Ethical approval: Not required.

1 Nyström L, Rutqvist LE, Wall S, Lindgren A, Lindqvist M, Ryden S, et al. Breast cancer screening with mammography: overview of Swedish randomised trials. Lancel 1993;341:973-8

2 Mammography screening evaluation group, H:S Copenhagen Hospital Corporation. Mammography screening for breast cancer in Copenhagen April 1991-March 1997. APMIS 1998;106(suppl 83):1-44.

3 Gøtzsche PC, Olsen O. Is screening for breast cancer with mammography justifiable? Lancet 2000;355:131-6.

4 Olsen O, Gøtzsche PC. Cochrane review on screening for breast cancer with mammography. Lancet 2001;358:1340-2.

5 Olsen AH, Jensen A, Njor SH, Villadsen E, Schwartz W, Vejborg I, et al. Breast cancer incidence after the start of mammography screening in Denmark. Br J Cancer 2003;88:362-5.
6 Olsen AH, Njor SH, Vejborg I, Schwartz W, Dalgaard P, Jensen M-B et al. A model for determining the effect of mammography service screening. Acta Oncologica 2005 (in press)

$7 \begin{aligned} & \text { Vress). } \\ & \text { Vejborg I, Olsen AH, Jensen M-B, Rank F, Tange UB, Lynge E. Early outcome of mam- }\end{aligned}$ mography screening in Copenhagen 1991-99. J Med Screen 2002;9:115-9.

8 Fischerman K, Mouridsen HT. Danish Breast Cancer Cooperative Group (DBCG). Structure and results of the organisation. Acta Oncologica 1988;27:593-6.

9 Andreasen AH, Mouridsen HT, Andersen KW, Lynge E, Madsen M, Olesen KP. Improved prognosis of breast cancer. Ugeskr Leeger 1994;156:6512-7.

10 Andreasen AH, Andersen KW, Madsen M, Mouridsen H, Olesen KB, Lynge E. Regional trends in breast cancer incidence and mortality in Denmark prior to mammographic screening. Br J Cancer 1994;70:133-7.

11 Blanks RG, Moss SM, McGahan CE, Quinn MJ, Babb PJ. Effect of NHS breast screening programme on mortality from breast cancer in England and Wales, 1990-8: coming programme on mortality from breast cancer in England and W
parison of observed with predicted mortality. BMJ 2000;321:665-9.

12 Otto SJ, Fracheboud J, Looman CWN, Broeders MJM, Boer R, Hendriks JHCL, et al. Initiation of population-based mammography screening in Dutch municipalities and effect on breast-cancer mortality: a systematic review. Lancet 2003;361:1411-17.

13 Jonsson H, Nyström L, Törnberg S, Lenner P. Service screening with mammography of women aged 50-69 years in Sweden: effects on mortality from breast cancer. J Med Screen 2001;8:152-60.

14 Duffy SW, Tabar L, Chen HH, Holmqvist M, Yen MF, Abdsalah S, et al. The impact of organized mammography service screening on breast carcinoma mortality in seven Swedish counties. Cancer 2002;95:458-69.

15 Nyström L, Andersson I, Bjurstam N, Frisell J, Nordenskjöld B, Rutqvist LE. Long-term Nyström L, Andersson I, Bjurstam N, Frisell J, Nordenskjöld B, Rutqvist LE. Long-term
effects of mammography screening: updated overview of the Swedish randomised trieffects of mammography screen
als. Lancet 2002;359:909-19.

16 Alexander F, Anderson TJ, Brown HK, Forrest APM, Hepburn W, Kirkpatrick AE, et al. 14 years of follow-up from the Edinburgh randomised trial of breast-cancer screening. Lancet 1999;353:1903-8.

17 Njor SH, Olsen AH, Bellstrøm T, Dyreborg U, Bak M, Axelsson C, et al. Mammography screening in the county of Fyn November 1993-December 1999. APMIS 2003;111(suppl 110):1-33.

(Accepted 15 November 2004)

doi 10.1136/bmj.38313.639236.82

Institute of Public Health, University of Copenhagen, Blegdamsvej 3, DK-2200 Copenhagen N, Denmark

Peter Dalgaard associated professor

Elsebeth Lynge professor

Sisse H Njor statistician

Anne Helene Olsen statistician

University Hospital Copenhagen, Blegdamsvej 9, DK-2100 Copenhagen $\varnothing$,

Denmark

Ilse Vejborg chief physician, Centre of Diagnostic Imaging

Henning Mouridsen professor, Department of Oncology

Ulla Brix Tange staff specialist, Department of Oncology

Fritz Rank chief physician, Department of Pathology

Mogens Blichert-Toft professor, Danish Breast Cancer Cooperative Group

Maj-Britt Jensen statistician, Danish Breast Cancer Cooperative Group

Mammography Screening Clinic, University Hospital Odense, Kløvervænget 10, DK-5000 Odense, Denmark

Walter Schwartz chief physician

Correspondence to: A H Olsen a.h.olsen@pubhealth.ku.dk 